\title{
THE INFLUENCE OF SALIVA CONTAMINATION ON UNIVERSAL ADHESIVE BONDING TOENAMEL AND DENTIN
}

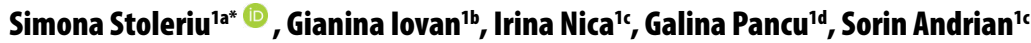 \\ 'Odontology-Periodontology and Fixed Prosthesis Department, Faculty of Dental Medicine „, Grigore T. Popa" University of Medicine and Pharmacy lași, \\ Iași, Romania
}

aDMD, PhD, Associate Professor

${ }^{b} \mathrm{DMD}, \mathrm{PhD}$, Professor

'DMD, PhD, Assistant Professor

${ }^{\mathrm{D} D M D}, \mathrm{PhD}$, Lecturer

'DMD, PhD, Professor

\section{ABSTRACT \\ DOI: https://doi.org/10.25241/stomaeduj.2019.6(4).art.2}

Introduction: The aims of the study were to investigate the enamel and dentin marginal seal of a universal adhesive system applied with etch and rinse and selfetch strategy and to evaluate the enamel and dentin marginal microleakage in case of saliva contamination on different steps of the adhesive application by dye penetration assessment.

Methodology: Thirty class $V$ cavities were prepared on the buccal face (group I- etch and rinse application of universal adhesive system) and the lingual face (group II- self-etch application of universal adhesive system) of molars and bicuspids. In each group 3 subgroups were created according to the moment of the saliva contamination: subgroup 1- no contamination, subgroup 2-contamination before light curing the adhesive, subgroup 3-contamination after light curing the adhesive. The dye penetration at the adhesive interface was evaluated according to a 4-score scale.

Results: In both groups increased enamel and dentin microleakage was recorded in subgroups 2 and 3 when comparing to subgroup 1. In group I saliva contamination before and after light curing the adhesive resin led to similar mean value of dentin microleakage. Increased values of microleakage were recorded in group II when comparing to group I in the subgroups where contamination with saliva was done before light curing the adhesive resin.

Conclusions: Saliva contamination of the adhesive system after light curing increased enamel microleakage only when the adhesive system was applied with etch and rinse strategy. Increased dentin microleakage after contamination was recorded with both strategies of universal adhesive system application.

Keywords: Universal Adhesive System; Adhesion; Saliva Contamination;

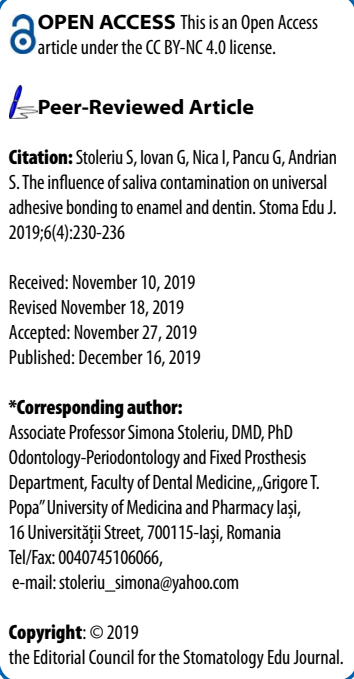

Copyright: $\odot 2019$

the Editorial Council for the Stomatology Edu Journal. Etch and Rinse; Self-Etch.

\section{Introduction}

Adhesion is the attraction of two different surfaces placed into direct tight contact determined by intermolecular forces that act at a relatively low distance [1]. The name adhesive indicates a material, most frequently a viscous fluid that joins (bonds) together two substrates and favours the transfer of forces from one surface to another [2]. There are many mechanisms implicated in the bonding process, four mechanisms being implicated in bonding to the tooth structure: 1. mechanical adhesion (resin penetration into the dental structure and resin tags formation); 2 . adhesion by sorption (chemical adhesion to the inorganic part of the tooth structure - hydroxyapatite - or to the organic part - mostly to type I collagen by Van der Waals or dipol-dipol forces, by hydrogen or covalent bonds); 3. adhesion by diffusion (substances precipitation on the tooth surface to which resin monomers can bond mechanically or chemically); 4. combination of the three mechanisms mentioned above $[3,4]$. The adhesion mechanism of bonding systems represents the replacement of removed tooth minerals with resin monomers in order that the polymers could be micromechanically integrated into the dental structure $[5,6]$. There are some conditions to obtain a good adhesion: the surface substrate should be clean, the adhesive should perfectly wet the substrate, there should be a good intimal adaptation of the adhesive to the adherent, and the bond strength should be high enough to resist to debonding forces [7]. Acid etching was recommended more than sixty 
Table 1. Details regarding the restoration protocol in sugroups 1-5 of groups I and II.

\begin{tabular}{|c|c|}
\hline \multicolumn{2}{|r|}{ Group I } \\
\hline $\begin{array}{l}\text { Subgroup } 1 \\
\text { (control) }\end{array}$ & $\begin{array}{l}\text { Phosphoric acid application for } 15 \text { seconds on enamel and dentin; washing } \\
\text { with water; drying with a brush applicator; scrubbing the surface with } \\
\text { adhesive resin for } 20 \text { seconds, air drying for } 5 \text { seconds, lightcure for } 20 \\
\text { seconds; composite resin restoration }\end{array}$ \\
\hline Subgroup 2 & $\begin{array}{l}\text { Phosphoric acid application for } 15 \text { seconds on enamel and dentin; washing } \\
\text { with water; drying with a brush applicator; scrubbing the surface with } \\
\text { adhesive resinfor } 20 \text { seconds; saliva contamination for } 5 \text { seconds, air drying } \\
\text { for } 5 \text { seconds, lightcure for } 20 \text { seconds; composite resin restoration }\end{array}$ \\
\hline Subgroup 3 & $\begin{array}{l}\text { Phosphoric acid application for } 15 \text { seconds on enamel and dentin; washing } \\
\text { with water; drying with a brush applicator; scrubbing the surface with } \\
\text { adhesive resin for } 20 \text { seconds; air drying for } 5 \text { seconds; lightcure for } 20 \\
\text { seconds; saliva contamination for } 5 \text { seconds; air drying for } 5 \text { seconds, } \\
\text { composite resin restoration }\end{array}$ \\
\hline \multicolumn{2}{|r|}{ Group II } \\
\hline Subgroup 1 & $\begin{array}{l}\text { Scrubbing the surface with the adhesive resin for } 20 \text { seconds; air drying for } 5 \\
\text { seconds; lightcure for } 20 \text { seconds; composite resin restoration }\end{array}$ \\
\hline Subgroup 2 & $\begin{array}{l}\text { Scrubbing the surface with the adhesive resin for } 20 \text { seconds; saliva } \\
\text { contamination for } 5 \text { seconds; air drying for } 5 \text { seconds; lightcure for } 20 \\
\text { seconds; composite resin restoration }\end{array}$ \\
\hline Subgroup 3 & $\begin{array}{l}\text { Scrubbing the surface with the adhesive resin for } 20 \text { seconds; air drying for } \\
5 \text { seconds; lightcure for } 20 \text { seconds; saliva contamination for } 5 \text { seconds; air } \\
\text { drying for } 5 \text { seconds; composite resin restoration }\end{array}$ \\
\hline
\end{tabular}

years ago by Buonocuore to facilitate the adhesion of composite resin to the enamel [8]. By etching the smooth surface of enamel is changed into an irregular surface and the surface energy increases. The resin will penetrate the rough surface by capillary action and resin tags will result. This is the fundamental mechanism of bonding to enamel [9]. Bonding to dentin relies mostly on monomer's penetration within the collagen fibers exposed after acid etching. The presence of dentin fluid on the cut dentin surface and the smear layer formation by fragments of hydroxyapatite crystals and denatured collagen might complicate the adhesion to dentin [10]. Optimal adhesion is obtained by completely removing the smear layer (etch and rinse strategy) or incorporating it into the adhesive layer (self-etch strategy) [11]. The technique of restoration using composite resins is very sensitive to moisture, so good isolation of the operating field is mandatory to obtain a good adhesion. The clean and high energy state of the surface is mandatory to obtain strong bonding. In some particular clinical situation ideal isolation cannot be achieved and oral biofilms, saliva, other oral fluids, and organic debris might contaminate the tooth surface prepared for adhesion [12].

An acid conditioned enamel surface rapidly absorbs salivary components, which decreases the surface energy and impairs the surface for adhesion [13]. A review of the literature regarding the influence of saliva contamination on adhesive dentistry has shown that $77 \%$ of the three-step adhesive systems, $46 \%$ of the two-step adhesive systems, $81.5 \%$ of the two-step self-etch adhesives and $73.3 \%$ of the onestep self-etch adhesives may be adversely influenced in their bond quality [14]. Universal adhesive systems are the latest class of bonding agents released on the market. Here are some of their characteristics: they can be used for direct and indirect restorations, they can react with different substrates, they can be used with etch and rinse, self-etch or selective etch strategy according to the clinical situation and the personal preference of the practitioner [15]. They should be hydrophilic in order to wet the dentin surface well, they should be hydrophobic not to allow water sorption and hydrolysis after polymerization, they should be acidic enough to etch well, but not so acidic in order not to destroy some of the initiators [7]. There are only few data in the literature regarding the bonding of universal adhesive systems in case of substrate contamination $[16,17]$. The aims of the study were to investigate the enamel and dentin marginal seal of a universal adhesive system applied in etch and rinse and self-etch strategy, to evaluate the enamel and dentin marginal microleakage in case of saliva contamination on different steps of the adhesive application by dye penetration assessment.

\section{Materials and methods}

Thirty molars and bicuspids having no caries lesions buccal and lingual on the cervical third of the crown no wear lesions or other defects after the extraction were chosen for this study. Class $V$ cavities having a depth of $3 \mathrm{~mm}$ and the cervical margin placed $2 \mathrm{~mm}$ apically of the enamel-cementum junction 
Table 2. Microleakage scores on enamel and dentin margins in group I.

\begin{tabular}{|c|c|c|c|c|c|}
\hline & Score 0 & Score 1 & Score 2 & Score 3 & $\begin{array}{l}\text { Mean scores } \\
\text { value }\end{array}$ \\
\hline \multicolumn{6}{|c|}{$\begin{array}{l}\text { Grup I - enamel (Statisticaly significant results-uppercase, No statisticaly significant results-lowercase } \\
\text { subgroup 1-subgroup 2: A,a; subgroup 1-subgroup 3: B,b; subgroup 2-subgroup 3: C,c) }\end{array}$} \\
\hline Subgroup 1 & 10 & - & - & - & $0(\mathrm{aB})$ \\
\hline Subgroup 2 & 8 & 2 & - & - & $0.2(\mathrm{a}, \mathrm{c})$ \\
\hline Subgroup 3 & 6 & 4 & - & - & $0.4(B, C)$ \\
\hline \multicolumn{6}{|c|}{$\begin{array}{l}\text { Grup I - dentin (Statisticaly significant results-uppercase, No statisticaly significant results-lowercase, } \\
\text { subgroup 1-subgroup 2: D,d; subgroup 1-subgroup 3: E,e; subgroup 2-subgroup 3: F,f) }\end{array}$} \\
\hline Subgroup 1 & 10 & - & - & - & $0(D, E)$ \\
\hline Subgroup 2 & 6 & 2 & 2 & - & $0.6(D, f)$ \\
\hline Subgroup 3 & 6 & 2 & 2 & - & $0.6(E, f)$ \\
\hline
\end{tabular}

were prepared on these areas. The buccal cavities were included in group I and the lingual cavities in group II. All the cavities were restored using the same composite resin (Ceram $X$ sphere TEC one, Dentsply Sirona - batch number 0894) and a universal adhesive system (Prime and Bond Active, Dentsply Sirona - batch number 1810000151) applied with two different strategies: etch and rinse (group I) and self-etch (group II). In each group 3 subgroups were created according to the moment of saliva contamination during the adhesive system application (table 1).

Human stimulated saliva was used for contamination. The saliva was collected from a single person in two different days, at the same hour, after a diet break of 5 hours. The same quantity of saliva $(0.1 \mathrm{~mL})$ was applied in contamination session using a syringe. The composite resin used for the restoration was applied in two layers of $1.5 \mathrm{~mm}$, each one being polymerized using a LED lamp (LED B, Guilin Woodpecker Medical Instrument Co., Ltd., Guilin, China) with a wavelength of $420-480 \mathrm{~nm}$. A constant light intensity of $1000 \mathrm{~mW} /$ $\mathrm{cm}^{2}$ was used during the experiment and the light intensity was tested before the beginning of the test using a Demetron ${ }^{\circledast}$ LED radiometer (Kerr Dental, Bioggio, Switzerland). After restoration the teeth were submersed in distilled water for 24 hours, then the external surfaces of the buccal and lingual tooth faces were covered with water resistant varnish, except a $1 \mathrm{~mm}$ area around the restorations, then they were submersed in methylene blue solution $2 \%$ $(\mathrm{pH}=7)$ for 24 hours. The teeth were sectioned in a buccal-lingual direction using diamond disks at low speed, under water cooling (Komet Dental, Brasseler $\mathrm{GmbH} \&$ Co., Lemgo, Germany). The tooth sections were evaluated using an optical microscope (CarlZeiss AXIO Imager A1m) at 10X magnification and the dye penetration at the enamel (occlusal) and dentin (cervical) margins of the cavity was assessed using a 4-score scale: 0 - no dye penetration; 1 - dye penetration less than half of the wall; 2 - dye penetration more than half but less than the entire wall; 3 - complete dye penetration on the wall until the axial wall of the cavity. The Mann-Whitney statistical test was used to compare the results in groups and subgroups.

\section{Results}

The scores of dye penetration in subgroups 1-3 of groups I and II are presented in tables 2 and 3. In both groups increased enamel microleakage was recorded in subgroups 2 and 3 when comparing to subgroup 1. Group I contamination with saliva after polymerization of the adhesive resin led to the highest microleakage mean value. Significantly statistic result was obtained when comparing enamel microleakage in subgroups 1 and 3 from group I $(p=0.029<0.05)$, but no statistically significant results were obtained when comparing enamel microleakage in subgroups 1 and $2(p=0.145>0.05)$. In group II statistically significant results were obtained when comparing enamel microleakage in subgroups 2 and 3 when comparing to subgroup $1(p=0.030<0.05$ and $p=0.005<0.05)$. In group II no statistically significant differences of values of microleakage were recorded in all subgroups when comparing to group I $(p=1.000>0.05)$.

At the dentin margins increased values of microleakage were recorded in subgroups 2 and 3 when comparing to control in both groups $(p=0.030<0.05$, $p=0.030<0.05, \quad p=0.004<0.05$, and $p=0.005<0.05$ respectively). In group I saliva contamination before and after light curing the adhesive resin led to similar mean values of microleakage. Increased values of microleakage were recorded in group II when comparing to group I in the subgroups where contamination with saliva of the adhesive resin was done before light curing. Irrespective of the moment of saliva contamination, the microleakage values at the dentin margins in etch and rinse strategy of 
Table 3. Microleakage scores on enamel and dentin margins in group II.

\begin{tabular}{|l|c|c|c|c|c|}
\hline & Score 0 & Score 1 & Score 2 & Score 3 & $\begin{array}{c}\text { Mean scores } \\
\text { value }\end{array}$ \\
\hline $\begin{array}{l}\text { Grup II- enamel (Statisticaly significant results-uppercase, No statisticaly significant results-lowercase; } \\
\text { subgroup 1-subgroup 2: A,a; subgroup 1-subgroup 3: B,b; subgroup 2-subgroup 3: C,c) }\end{array}$ & -2 & - & $0.2(A, B)$ \\
\hline Subgroup 1 & 8 & 2 & - & - & $0.6(A, c)$ \\
\hline Subgroup 2 & 4 & 6 & 2 & - & $0.8(B, c)$ \\
\hline Subgroup 3 & 4 & 4 & - & - & $0(D, E)$ \\
\hline $\begin{array}{l}\text { Grup II - dentin (Statisticaly significant results-uppercase, No statisticaly significant results-lowercase; } \\
\text { subgroup 1-subgroup 2: D,d; subgroup 1-subgroup 3: E,e; subgroup 2-subgroup 3: F,f) }\end{array}$ \\
\hline Subgroup 1
\end{tabular}

adhesive application were not higher than those at enamel margins (subgroup $2 \mathrm{p}=0.260>0.05$, subgroup $3 \mathrm{p}=0.342>0.05)$. In the self-etch strategy of the adhesive application similar values of microleakage were recorded at enamel and dentin margins. (in all subgroups $p$ value was $1.00>0.05$ )

\section{Discussion}

Composite resins are the most frequently used materials for direct restorations due to their mechanical and optical properties and to the conservative preparation of the teeth needed [18]. A lot of factors can contribute to the marginal leakage of composite resins into the oral cavity: the size and the shape of the cavity, the type of the dental substrate, the type and the placement of the prepared cavity margins, and the technique of restoration [19]. Marginal adaptation of the adhesive system to the tooth structure should prevent the microleakage onset and future caries lesion adjacent to the restoration, saliva infiltration, pulp irritation or fracture of the restoration $[20,21]$. Progress was made in time to improve the composite resins bonding to enamel and dentin. Phosphoric acid was the first acid used for tooth etching, but the newer generations of bonding agents contain acidic primers that etch and prime simultaneously. Simplifying the clinical steps of bonding application led to the release of all-in-one adhesive systems that can etch, prime and bond in just one step. Unfortunately, one-step self-adhesive systems do not etch the enamel as efficiently as etch and rinse systems and as a consequence the marginal seal might be incomplete. For multiple steps etch and rinse adhesive systems increase risk for dentin dehydration because after drying subsequent collapse of the collagen fibers might occur. Also, residual unremoved acid after an incorrect washing might lead to prolonged demineralization of the dentin and a possible closure of the spaces between the collagen fibers with reactive products [22].
The bond strength of the newer adhesive systems has been permanently improved, so the mild twostep self-etching systems are a viable alternative to the three or two-step etch and rinse systems [23]. This performance relies on their $\mathrm{pH}$ of 2 , acidic monomers being capable to create enough microretention in enamel. Regarding dentin, the self-etch adhesive systems have also demonstrated similar adhesion to the total etch systems [24]. Unfortunately onestep self-etch adhesive systems did not show the same good adhesion to enamel when comparing to total etch adhesive systems and additional step of selective etching is needed to improve enamel bonding [25-27]. One of the advantages of universal bonding systems is their possibility of application with etch and rinse and self-etch strategies, but the major goal of them being introduced into the market was the one-step self-etch application. Functional monomers, like the 10-MDP (10-methacryloyl oxide decyl hydrogenphosphate) molecule that chemically bond to hydroxyapatite simultaneously with the etching and adhesive resin penetration into the tooth structure are responsible for this particular behavior [25,27-29].

Studies have shown a similar bonding performance of universal adhesives when comparing to the selfetch adhesives and etch and rinse adhesives [16]. In the present study, the universal adhesive system application led to similar microleakage at enamel and dentin margins irrespective of the strategy of application. Some previous studies have shown increased dentin microleakage when comparing to enamel for etch and rinse and self-etch adhesive systems [30,31]. Due to increased mineral content and to a more homogenous structure, a better adhesion and a lower marginal leakage to enamel are achieved when comparing to dentin. Dentin has a lower mineral content and the organic part is mainly composed of a dense network of type I collagen fibers and it has dentin tubules. Branches 
of these tubules are denser on root dentin than on crown dentin. Etching with phosphoric acid or with acidic primers changes the surface morphology and chemical composition.Moreover, the tubules orientation can change the hybrid layer formation [32]. The results of some other studies also showed that the enamel marginal leakage was similar when universal bonding systems were used with the etch and rinse or self-etch strategy which led to the conclusion that an additional step of selective enamel etching is not necessary [16]. The same study showed similar bonding to dentin for the universal bonding systems applied in both strategies. That might be explained by the particular chemical composition of the bonding agent that was tested in the study (Scotchbond Universal Adhesive, 3M, St. Paul, MN, USA). The10-MDP molecule creates stable chemical bond and VitreBond copolymer ensures the long-term adhesion on wet or dry dentin $[25,28]$. Studies that investigated the adhesion of a universal bonding system used in class $\mathrm{V}$ cavities restoration showed similar values of microleakage irrespective of the strategy of application [27]. In class $V$ restorations were the gingival margin is located apically of the enamel-dentin junction the moisture control is difficult to achieve. Sulcular fluid and saliva (when a proper isolation is not possible) can contaminate the surface. The multiple step adhesive systems are more prone to failure due to high risk of substrate contamination when comparing to simplified adhesive systems. The adhesion of some self-etch bonding systems seems to be less efficient in dentin due to moisture that blocks the complete diffusion of the adhesive resin in the collagen network. Water sorption also leads to phase separation between hydrophobic resins and hydrophilic primers in the chemical composition of the bonding agent. Saliva glycoproteins adsorbed into the unpolymerized adhesive layer may act as a barrier that lowers the humectant character of the resin [27]. Also, water incorporation in incompletly polymerized resin might interfere with future co-polimerization with the next resin layer. In a literature review of the adverse effects of contamination in adhesive dentistry the authors

\section{References}

1. ASTM D907. Standard Terminology of Adhesives. West Conshohocken, PA, US: ASTM International (ASTM); 2015.

2. Ritter AV, Boushell LW, Walter R. Sturdevant's Art and Science of Operative Dentistry. Seventh ed. St. Louis, Ml: Elsevier; 2019.

3. Van Meerbeek B, Vargas $M$, Inoue $S$, et al. Adhesives and cements to promote preservation dentistry. Oper Dent. 2001;26(Suppl 6):119-144. Google Scholar

4. Yoshida Y, Nagakane K, Fukuda R, et al. Comparative study on adhesive performance of functional monomers. J Dent Res. 2004;83(6):454-458.

[Full text links] [CrossRef] [PubMed] Google Scholar Scopus

5. Hilton TJ. Can modern restorative procedure and material reliably seal cavities? In vitro investigations. Part 1. Am J Dent. 2002;15(3):198-210. [CrossRef] [PubMed] reported that contamination had a deleterious effect on $73.3 \%$ of the 30 evaluated one-step self-etch adhesive systems. The negative effects occurred either when contamination was simulated before and after the adhesive polymerization; it always affected the enamel and in $66.6 \%$ of the cases it affected the dentin [17]. Nair et al. reported different results than our study, but in their paper both $7^{\text {th }}$ generation of adhesives and the universal adhesives were included in the category of one-step self-etch adhesives, so it is not known for sure how many of the investigated adhesive systems were really universal adhesive systems. The limitations of our study are represented by the low number of the samples, the microleakage evaluation immediately after restoration, and the standardized time for contamination (which is relevant only in fewer clinical situations). The present study simulated clinical conditions that are likely to rarely appear.

\section{Conclusions}

Given the conditions of this study, saliva contamination after the adhesive system light curing increased the enamel microleakage only when the adhesive system was applied in etch and rinse strategy, but increased the microleakage in dentin with etch and rinse and self-etch strategies.

Contamination with saliva before the adhesive system light cure did not change the enamel microleakage irrespective of the strategy of adhesive application, but increased the dentin microleakage in both strategies.

\section{Author Contributions}

SS: concept, experimental design, data gathering and analysis, manuscript writing, Gl: concept, analysis and interpretation of the results, IN: protocol, data collection, analysis and interpretation of the results, PG: experimental design, data gathering and analysis, SA: interpretation of the results, manuscript proofreading.

\section{Acknowledgments}

Not applicable. The study was self-funded.

6. Breschi L, Mazzoni A, Ruggeri A, et al. Dental adhesion review: aging and stability of the bonded interface. Dent Mater. 2008;24(1):90-101. [Full text links] [CrossRef] [PubMed] Google Scholar Scopus

7. Alex G. Universal adhesives: the next evolution in adhesive dentistry? Compend Contin Educ Dent. 2015;36(1):15-26; quiz 28, 40. [PubMed] Google Scholar

8. Buonocore MG. A simple method of increasing the adhesion of acrylic filling to enamel surfaces. J Dent Res. 1955;34(6):849-853.

[Full text links] [PubMed] Google Scholar Scopus

9. Suppa P, Breschi L, Ruggeri A, et al. Nanoleakage within the hybrid layer: a correlative FEISEM/TEM investigation. J Biomed Mater Res B Appl Biomater. 2005;73(1):7-14.

[Full text links] [CrossRef] [PubMed] Google Scholar Scopus

10. Bowen RL, Eick JD, Henderson DA, Anderson DW. Smear layer: removal and bonding 
considerations. Oper Dent. 1984;9(Suppl3):30-34. [PubMed] Google Scholar Scopus

11. Pashley $\mathrm{DH}$, Carvalho RM. Dentin permeability and dentin adhesion. J Dent. 1997;25(5):355-372. [Full text links] [CrossRef] [PubMed] Google Scholar Scopus

12. Price RB, Dérand T, Andreou P, Murphy D. The effect of two configuration factors, time, and thermal cycling on resin to dentin bond strengths. Biomaterials. 2003;24(6):1013-1021. [Full text links] [CrossRef] [PubMed] Google Scholar Scopus

13. Buonocore MG. Caries prevention in pits and fissures sealed with an adhesive resin polymerized by ultraviolet light: a two-year study of a single adhesive application. J Am Dent Assoc. 1971;82(5):1090-1093. [Full text links] [CrossRef] [PubMed] Google Scholar Scopus

14. Marshal SJ, Bayne SC, Baier R, et al. A review of adhesion science. Dent Mater. 2010;26(2):e11-e16. Google Scholar

15. Suh BI, Feng L, Pashley DH, Tay FR. Factors contributing to the incompatibility between simplified-step adhesives and chemically-cured or dual-cured composites. Part III. Effect of acidic resin monomers. J Adhes Dent. 2003;5(4):267-282. [PubMed] Google Scholar Scopus

16. Motevaselian $F$, Yassine $E$, Mirzaee $M$, et al. In vitro microleakage of class $V$ composite restorations in use of three adhesive systems. J Islam Dent Assoc Iran. 2016;28(1):14-19. Google Scholar

17. Nair P, Hickel R, llie N. Adverse effects of salivary contamination for adhesives in restorative dentistry.

18. A literature review. Am J Dent. 2017;30(3):156-164. [PubMed] Google Scholar Scopus

19. Ferracane JL. Resin composite--state of the art. Dent Mater. 2011;27(1):29-38.

[Full text links] [CrossRef] [PubMed] Google Scholar Scopus

20. Araujo FO, Vieira LCC, Monteiro Junior S. Influence of resin composite shade and location of the gingival margin on the microleakage of posterior restorations. Oper Dent. 2006;31(5):556-561. [Full text links] [CrossRef] [PubMed] Google Scholar Scopus

21. FrancoEB, Gonzaga Lopes L, Lia MondelliRF, et al.Effect of the cavity configuration factor on the marginal microleakage of esthetic restorative materials. Am JDent. 2003;16(3):211-214. [PubMed] Google Scholar Scopus

22. Hilton TJ, Ferracane JL, Brome JC. Summitt's fundamentals of operative dentistry: a contemporary approach. Fourth ed. Hanover Park, IL, US: Quintessence Publishing Co Inc; 2013.

23. Nakabayashy N, Pashley D. Hybridzation of dental hard tissues. First ed. Chicago, IL, US: Publishing Co Inc; 1998. Google Scholar
24. Giannini M, Makishi P, Ayres AP, et al. Self-etch adhesive systems: a literature review. Braz Dent J. 2015;26(1):3-10. [Full text links] [CrossRef] [PubMed] Google Scholar Scopus

25. Gupta A, Tavane P, Gupta PK, et al. Evaluation of microleakage with total etch, self etch and universal adhesive system in class $V$ restoration: an in vitro study. J Clin Diagn Res. 2017;1(4):ZC53-ZC56. [Full text links] [PubMed] Google Scholar Scopus

26. Peumans $\mathrm{M}$, De Munck J, Van Landuyt $\mathrm{KL}$, et al. Eight-year clinical evaluation of a 2-step selfetch adhesive with and without selective ename etching. Dent Mater. 2010;26(12):1176-1184. [Full text links] [CrossRef] [PubMed] Google Scholar Scopus

27. Arami S, Shahabi S, Tabatabaie M, et al. Assessing microleakage of composite restorations in class $\mathrm{V}$ cavities prepared by Er:YAG laser irradiation or diamond bur.

28. J Conserv Dent. 2014;17(3):216-219. Google Scholar Scopus

29. Perdigão J, Kose C, Mena-Serrano AP, et al. A new universal simplified adhesive: 18-month clinical evaluation. Oper Dent. 2014;39(2):113-127. [Full text links] [CrossRef] [PubMed] Google Scholar Scopus

30. Mena-Serrano A, Kose C, De Paula EA, et al. A new universal simplified adhesive: 6-month clinical evaluation. J Esthet Restor Dent. 2013; 25(1):55-69. [Full text links] [CrossRef] [PubMed] Google Scholar Scopus

31. Muñoz MA, Luque-Martinez I, Malaquias $P$, et al. In Vitro longevity of bonding properties of universal adhesives to dentin. Oper Dent 2015:40(3):282-292. [Full text links] [CrossRef] [PubMed] Google Scholar Scopus

32. Koliniotou-Koumpia E, Dionysopoulos $P$, Koumpia $E$. In vivo evaluation of microleakage from composites with new dentin adhesives. J Oral Rehabil. 2004;31(10):1014-1022. [Full text links] [CrossRef] [PubMed] Google Scholar Scopus

33. Alavi AA Kianimanesh N. Microleakage of direct and indirect composite restorations with three dentin bonding agents. Oper Dent. 2002;27(1):19-24. [PubMed] Google Scholar Scopus

34. Tuncer D, Celik C, Cehreli SB, Arhun N. Comparison of microleakage of a multi-mode adhesive system with contemporary adhesives in class II resin restorations. J Adhes Sci Technol. 2014;28(13):1288-1297. [CrossRef] Google Scholar Scopus

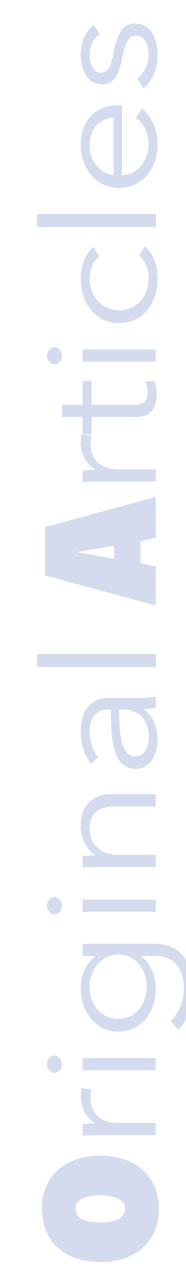

Simona STOLERIU

DMD, PhD, Associate Professor Odontology-Periodontology and Fixed Prosthesis Department Faculty of Dental Medicine "Grigore T. Popa" University of Medicine and Pharmacy laşi Iaşi, Romania

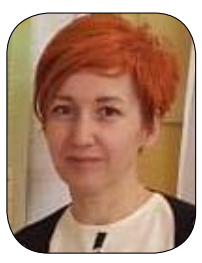

\section{cVI}

Simona Stoleriu graduated from the Faculty of Dental Medicine, "Grigore T. Popa" University of Medicine and Pharmacy laşi, laşi, Romania in 1997. Since 1999 to present she has been assistant professor, lecturer and now associated professor teaching Cariology, at the Department of Odontology, Periodontology and Fixed Prosthodontics, Faculty of Dental Medicine, "Grigore T. Popa" University of Medicine and Pharmacy laşi, laşi Romania. As of 1998 she has been a dentist in a private practice. Major research interests: 1. restorative materials behavior in oral environment; 2 . clinical and in vitro studies regarding the etiology, and the preventive and restorative treatment of tooth wear lesions; 3 . dental hard tissues remineralization of carious lesions and erosive wear. 


\section{Ouestions}

\section{The mechanisms implicated in bonding to the tooth structure include three mechanisms, with ONE EXCEPTION:}

$\square$ a. Mechanical adhesion;

b. Adhesion by sorption;

ac. Electrostatic bonding;

$\square d$. Adhesion by diffusion.

\section{A review of the literature regarding the influence of saliva contamination on adhesive dentistry has shown that:}

口a. $17 \%$ of three-step adhesive systems adversely influence their bond quality;

bb. $26 \%$ of two-step adhesive systems adversely influence their bond quality;

ac. $81.5 \%$ of two-step self-etch adhesives adversely influence their bond quality;

ad. 3.3\% of one-step self-etch adhesives adversely influence their bond quality.

\section{The results of the present study demonstrated that:}

$\square$ a. Saliva contamination after adhesive system lightcure increased enamel microleakage only when the adhesive system was applied in etch and rinse strategy;

b. Saliva contamination after adhesive system lightcure increased enamel microleakage only when the adhesive system was applied in self-etch strategy;

口. Saliva contamination after adhesive system lightcure increased enamel microleakage only when the adhesive system was applied in selective etch strategy;

口d. Saliva contamination after adhesive system lightcure increased enamel microleakage both etch and rinse and self-etch strategies.

\section{Irrespective of the strategy of universal bonding application saliva contamination significantly increased the microleakage in:}

口a. Enamel;

b. Dentin;

ac. Enamel and dentin;

$\square d$. None of the answers are correct.

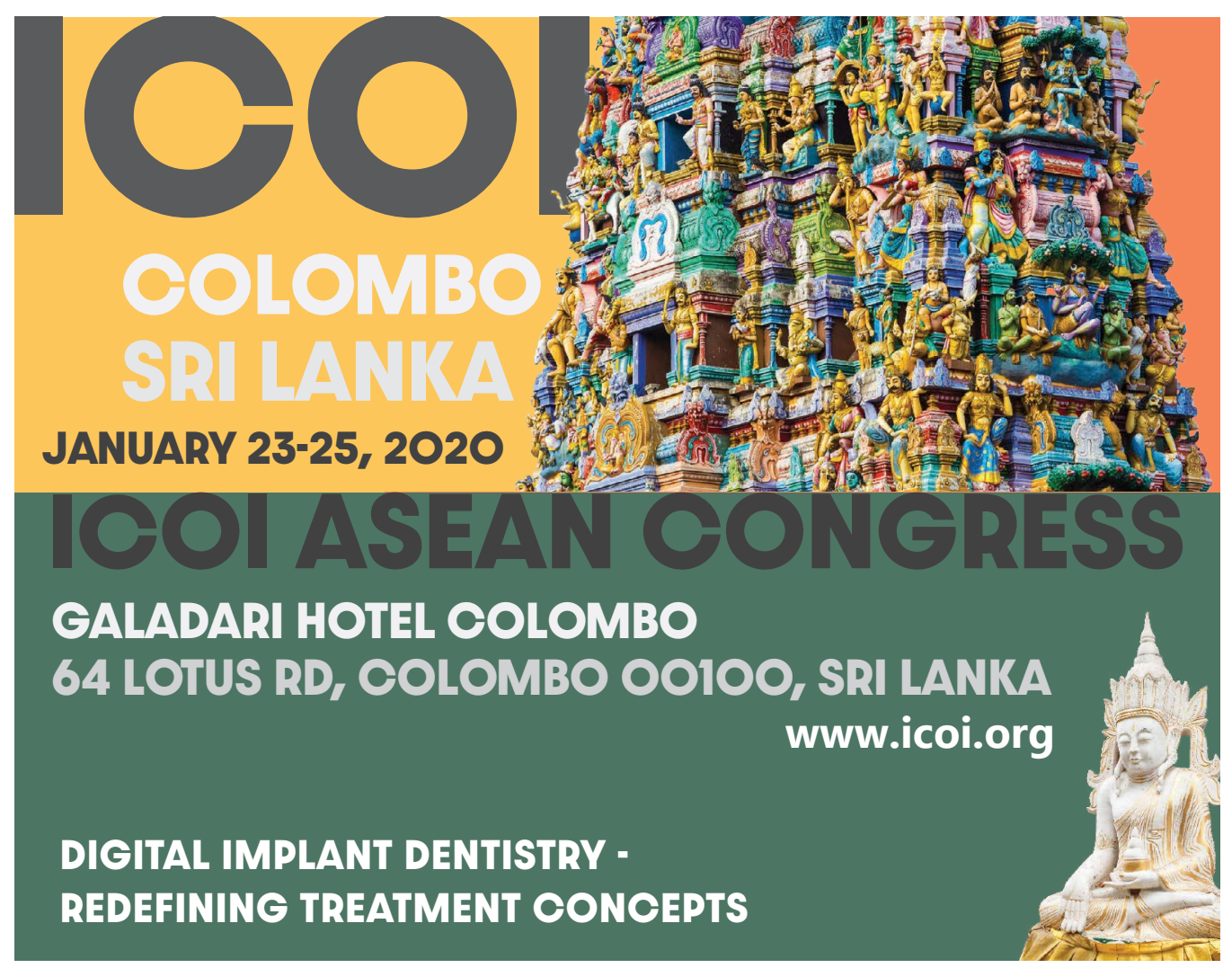

